\title{
MORPHOLOGICAL AND STRUCTURAL CHANGES IN MYOCARDIUM, LIPID AND CARBOHYDRATE METABOLISM DURING DIFFERENT OUTCOMES OF CHRONIC HEART FAILURE IN PATIENTS WITH ISCHEMIC HEART DISEASE AND DIABETES MELLITUS TYPE II
}

10.36740/WLek202010111

\author{
Ekaterina Yu. Lipakova' , Oleksandr V. Bilchenko' , Tetiana A. Rudenko' , Maksym 0. Holianishchev', \\ Olena V.Vysotska ${ }^{2}$, Liubov M. Rysovana ${ }^{3}$ \\ 'KHARKIV MEDICAL ACADEMY OF POSTGRADUATE EDUCATION, KHARKIV, UKRAINE \\ 2NATIONAL AEROSPACE UNIVERSITY «KHARKIV AVIATION INSTITUTE», KHARKIV, UKRAINE \\ ${ }^{3}$ KHARKIV NATIONAL MEDICAL UNIVERSITY, KHARKIV, UKRAINE
}

\begin{abstract}
The aim: To establish features of structural and functional changes in myocardium, carbohydrate and lipid metabolism, in patients with different outcomes of chronic heart failure (CHF), caused by IHD and DM type II.

Materials and methods: Examination of 100 patients who have CHF with IHF and DM type II was performed. Patients were divided in two groups, according to outcome: group I $(n=66)$ - patients with favorable outcome, mean age 60,0 $[55,8 ; 63,3]$ years, group II $(n=34)$ - unfavorable outcome of CHF, mean age 58,0 $[55,0 ; 60,3]$ years.

We analysed complaints, cardiologycal anamnesis, cardiovascular risk factors, physical examination data. Transthoracic echocardiography (TTE), carbohydrate and lipid panel were assessed to find out early specific signs of myocardial injury.

Results: We find out statistically significant associations between TTE results, lipid panel and CHF progression in study population.

Conclusions: Comparative analysis showed that degree of CHF in patients with IHD and DM type Il that have preserved LV EF is associated with: duration of DM and CHF, arterial hypertension (AH) level and degree of carbohydrate and lipid metabolism disturbances. Early TTE signs of unfavorable outcome are: increase of transmitral deceleration time (Dt), increase of mean PA pressure (PA MP) even in range lower the $20 \mathrm{mmHg}$.
\end{abstract}

KEY WORDS: carbohydrate metabolism, lipid metabolism, myocardium morpho-functional state

Wiad Lek. 2020;73(10):2165-2169

\section{INTRODUCTION}

There are 415 millions of patients around the world with diabetes mellitus (DM), $90 \%$ of them have DM type II [1]. Despite available scientific data about risk factors and DM-screening programs running, incidence of disease still increases. According to experts of International Diabetic Federation (IDF), in 2035 amount of people with DM type II will reach 592 millions, this is approximately every tenth. This shows significance of ongoing study on genotype and phenotype of DM to individualise treatment for this kind of patients [2].

DM type II leads to micro- and macrovascular complications, and after that ischemic heart disease (IHD). Epidemiological data shows that cardiovascular complications are the main reason of morbidity and mortality among patients with DM ( $80 \%$ of patients with DM type II mortality is connected to cardiovascular complications) [3]. Almost in 50\% patients that have IHD, diagnosis of the DM type II, impaired glucose tolerance or impaired fasting glucose is found first time. According to this, American Heart Association (AHA) established presence of DM type II as equivalent of high risk of vascular complications, that is comparable with present cardiovascular diseases [4].

Nowadays there is a big interest in pathophysiological mechanisms, responsible for changes in cardiomyocites during DM type II. Hyperglycemia leads to decrease in ability to resist oxidative stress by increase of glucose utilisation in citric acid pathway, increase in inflammatory response, that have influence on lipid metabolism and immune response, and leads to chronic inflammation in arterial vessel wall, endomyocardial fibrosis, necrosis and apoptosis of endothelial cells and cardyomiocytes $[1,5-8]$. This mechanisms combined with disorders of mineral metabolism, impairment of $\mathrm{Ca} 2+$ regulation of myofilament function, increase of active oxygen forms level, increased lipotoxycity, autonomic nervous system dysfunction, which one, according to progressive autonomic neuropathy, decrease vasodilative effect of sympathetic stimulation 
to coronary vessels resistance - thus accelerates coronary vessels calcification and appearance of CHF with DM type II $[1,5-9]$.

Despite present scientific data of DM type II influence on cardiovascular pathology, pathophysiology of myocardial ischemia during DM type II needs further investigation. One group of patients with DM type II have coronary artery disease that prevents normal blood flow to myocardium, another have microvascular changes without plaques, and absence or presence of endothelial dysfunction [7-9]. There is lack of data about main aspects of diabetic coronary microvascular dysfunction in structure of cardiovascular diseases, role of genetic types of ATP-dependent potassium channels that determine course of IHD by balancing coronary blood flow and cardiac performance [1, 6-9].

In modern era it's important to study mechanisms of development and specific clinical signs of CHF on the early stage. Investigations should lead to development of new methods and materials of prophylactic and treatment.

\section{THE AIM}

The objective of the study was to highlight patterns of cardiac morphology and function, lipid and carbohydrate metabolism during different courses of heart failure in patients with IHF and DM type II.

\section{MATERIALS AND METHODS}

We performed complex examination of 100 male patients with ischemic CHF with IHD and DM type II after in-hospital treatment. All patients signed an informed consent to participate in the study.

Examination was performed in therapy and cardiology departments of community-owned non-profit organization "City clinic of urgent and emergency medicine named after prof.A.I.Meschaninov" Kharkiv`s City Council, Ukraine, between February 2015 and January 2017.

Inclusion criteria: age between 50 and 70 years, CHF I-II functional class (FC) NYHA classification, LV EF $\geq 50 \%$ (according to criteria of European Society of Cardiology, 2016) [10], postinfraction cardiosclerosis with DM type II [11], glomerular filtration rate $(\geq 60$ $\mathrm{ml} / \mathrm{min} / 1,73 \mathrm{M}^{2}$ ).

Exclusion criteria: age more then 70 years, resistive arterial hypertension $(\mathrm{AH})$, secondary $\mathrm{AH}$, pulmonary artery hypertension, congenital and acquired heart diseases, presence of life-threatening ectopic arrhythmias, IHD that requires administration of short-acting nitrates more than two times a week, non-coronary myocardial diseases, chronic kidney disease with glomerular filtration rate GFR $<60 \mathrm{ml} / \mathrm{min} / 1,73 \mathrm{M}^{2}$, comorbidities: chronic obstructive pulmonary disease, bronchial asthma, anemia $\mathrm{Hb} \leq 90$ $\mathrm{g} / \mathrm{l}$, acute and chronic inflammatory myocardial diseases, postoperative state, oncological diseases, inflammatory gastro-intestinal diseases, haemopoetic diseases, traumatic injuries, alcohol abuse.
Patients were divided in two groups according to outcome: group I $(\mathrm{n}=66)$ - favorable outcome, mean age 60,0 $[55,8 ; 63,3]$ years, group II $(\mathrm{n}=34)$ - unfavorable outcome, mean age 58,0 $[55,0 ; 60,3]$ years.

Complaints, cardiological anamnesis, cardiovascular risk factors, physical examination data, laboratory and instrumental examination, including 12-leads ECG, were analysed. AP was measured three times on both brachial arteries in sitting position, not earlier than 30 minutes after physical exertion, with mean AP (MAP) calculated. Pulse AP (PAP) was measured as difference between systolic AP (sAP) and diastolic AP (dAP). Mean AP (MAP) calculations are : $\mathrm{MAP}=0,42 *(\mathrm{sAP}-\mathrm{dAP})+\mathrm{dAP}$.

Insulin plasma level was measured with Insulin Rapid AccuBind ELISA kits (Monobind Insulin, USA) agents. Serum glucose level was measured with biochemical analyser Flexor E («Vital Scientific N.V.», Netherlands), kit «Glucose SPL» colorimetric method GOD-POD. The homeostatic model assessment index (HOMA-ir) was calculated according to the formula:

fasting insulin (microU/L) $x$ fasting glucose $(\mathrm{nmol} / \mathrm{L}) / 22.5$. Homa-ir more than 2,5 was pointed as insulinresistence. Serum glycated hemoglobin (HbAlc) was measured with Liquidirect kit (Human GmbH, Germany).

We measured levels of total cholesterol (TC), high density lipoproteins (HDL), low density lipoproteins (LDL) and triglycerides (TG) by fermentative method with automated biochemical photometer Prestige 24 (Japan) with kits PZCORMAY S.A. (LQ CHOL; LQ TG; HDL DIRECT; LDL DIRECT, Poland) Also we calculate aterogenity index (AI) by the A.M. Klimov formula (1977) [12]: AI = (TC-HDL) / LDL.

Transthoracic echocardiography (TTE) was performed with SiemensACUSONIC 2000 (SiemensMedicalSolution, MountainView, USA), phased-array probe 3,5-7 MHz. Were measured: left ventricle end-diastolyc volume (LV EDV), left ventricle end-systolic volume (LV ESV), left atrium linear dimension (LALD), left ventricle ejection fraction (LV EF), transmitral deceleration time (Dt), left ventricle isovolumic relaxation time (IVRT), the ratio of peak velocity blood flow in early diastole to peak velocity flow in late diastole E/A ratio, the ratio of transmitral Doppler early filling velocity to tissue Doppler early diastolic mitral annular velocity (E/e'), mean pulmonary artery pressure (PA MP).

We measured endothelium dependent dilation in the brachial arteries (EDD). Degree of EDD was measured by reactive hyperemia, observed by wide-broad linear probe $5-12 \mathrm{MHz}$ in color doppler mode three times in left and right brachial arteries with 15 minutes interval, method by Celermajer D.S. modified after Ivanova A.V.

Observational period was 12 month after in-hospital treatment.

Standard medication was provided: $\beta$-blocker bisoprolol - 2,5-5 mg at morning, ACE inhibitor ramipril - 5-10 $\mathrm{mg}$ once at evening, amlodipin - 2,5-10 $\mathrm{mg}$ at evening, ASA - $75 \mathrm{mg}$ once after day meal, atorvastatin $20 \mathrm{mg}$ once after day meal, if additional hypotensive therapy needed indapamid $-2,5 \mathrm{mg}$ once at morning. 
Table I. Demography and anamnestic data of patients with IHD in both groups (Me [Q1; Q3])

\begin{tabular}{cccc}
\hline Indicator, unit & Group I, $(\mathbf{n}=\mathbf{6 6})$ & Group II, (n=34) & P \\
\hline Age, years & $60,0[55,8 ; 63,3]$ & $58,0[55,0 ; 60,3]$ & $>0,05$ \\
\hline IHD present, years & $6,0[5,0 ; 7,0]$ & $7,00[5,0 ; 10,0]$ & 0,014 \\
\hline DM type II present, years & $5,0[5,0 ; 6,0]$ & $6,0[5,0 ; 9,0]$ & 0,001 \\
\hline BMI $\left(\mathrm{kg} / \mathrm{m}^{2}\right)$ & $26,90[26,07 ; 27,85]$ & $25,59[24,80 ; 29,49]$ & $>0,05$ \\
\hline IHD family history, $\%$ & 40,9 & 58,8 & $>0,05$ \\
\hline DM type II family history, $\%$ & 36,4 & 58,8 & 0,03 \\
\hline
\end{tabular}

Table II. Clinical examination data of patients with IHD and DM type II in both groups

\begin{tabular}{cccc}
\hline Indicator, unit & Group I, $(\mathbf{n = 6 6 )}$ & Group II, (n=34) & P \\
\hline Physical exertion: impaired, $\%$ & 80,3 & 91,2 & $>0,05$ \\
\hline Smoking, $\%$ & 72,7 & 82,4 & $>0,05$ \\
\hline AH level: & & & \\
-AP from 160/100 to 179/99 $\mathrm{mmHg}, \%$ & 71,2 & 47,1 & 0,02 \\
-AP 180/110 mmHg and more, \% & 28,8 & 52,9 & 0,02 \\
\hline
\end{tabular}

Table III. Hemodynamic values, 6 min walk test in patients with IHD and DM type II (Me [Q1; Q3])

\begin{tabular}{cccc}
\hline Indicator, unit & Group I, (n=66) & Group II, (n=34) & P \\
\hline SAP, $\mathrm{mmHg}$ & $135,0[130,0 ; 145,0]$ & $145,0[140,0 ; 151,25]$ & 0,001 \\
\hline $\mathrm{pAP}, \mathrm{mmHg}$ & $50,0[45,0 ; 60,0]$ & $65,0[50,0 ; 75,0]$ & 0,001 \\
\hline $\mathrm{HR}, \mathrm{min}^{-1}$ & $68,5[65,75 ; 74,0]$ & $75,0[69,5 ; 78,0]$ & 0,001 \\
\hline 6 min walk test, $\mathrm{m}$ & $366,5[338,75 ; 389,0]$ & $371,0[355,0 ; 382,5]$ & $>0,05$ \\
\hline
\end{tabular}

Table IV. Carbohydrate metabolism characteristics in patients with IHD and DM type II (Me [Q1; Q3])

\begin{tabular}{|c|c|c|c|}
\hline Indicator, unit & Група I, (n=66) & Група II, (n=34) & $\mathbf{P}$ \\
\hline $\mathrm{HbA} 1 \mathrm{c}, \%$ & $7,0[6,6 ; 7,2]$ & $7,4[7,8 ; 7,6]$ & 0,001 \\
\hline Fasting glucose, $\mathrm{mmol} / \mathrm{l}$ & $6,05[5,78 ; 6,3]$ & $6,35[5,9 ; 6,9]$ & 0,004 \\
\hline Postprandial glucose, $\mathrm{mmol} / \mathrm{l}$ & $8,4[7,8 ; 8,8]$ & $8,9[8,4 ; 9,2]$ & 0,002 \\
\hline Insulin, mcME/ml & $19,2[15,3 ; 22,6]$ & $29,3[26,8 ; 33,3]$ & 0,001 \\
\hline HOMA-ir & $4,9[4,0 ; 6,4]$ & $8,2[7,3 ; 9,4]$ & 0,001 \\
\hline
\end{tabular}

Statistical analysis was performed with SPSS 19 software for Windows. Quantitative variables are described as: median (M), 25 and 75 quartiles (M [Q1; Q3]) qualitative data - as frequency of the events (\% from normal observations). In order to identify differences between independent samples was used Mann-Whitney U-criteria. Frequency of sign occurrence in gropus was compared by $\chi^{2}$ criteria.

\section{RESULTS AND DISCUSSION}

After 12 months of study, enrolled patients were divided in two groups depending on outcomes. Group I $(n=66)$ - favorable outcome of IHF, age 60,0 [55,8;63,3] years, group II $(\mathrm{n}=34)$ - unfavorable outcome, mean age 58,0 $[55,0 ; 60,3]$ years. There was no statistically significant difference in age $(\mathrm{p}>0,05)$ (Table 1$)$. In group II CHF progressed, that was characterized by LV EF decrease in 13 patients (38\%), diastolic dysfunction in $14(41 \%)$ patient, death in $7(20 \%)$ patients.
Duration of IHD varies from 5 to 10 years. Duration of DM type II - from 5 to 9 years. Family history of DM type II had $36,4 \%$ of patients in group I and $58,8 \%$ in group II $(p=0,03)$. Every patient with DM type was in subcompensated state (fasting glucose $<7,6 \mathrm{mmol} / \mathrm{l}$, glycated haemoglobin $<8,0 \%$ ).

During analysis of family and clinical history in both groups, CHF was significantly associated duration of IHD $(\mathrm{p}=0,014)$, and DM type II $(\mathrm{p}=0,001)$ Statistically significant difference in IHD family history appearance was not found in both groups ( $\mathrm{p}>0,05)$, also as in BMI ( $\mathrm{p}>$ 0,05) (Table 1).

During the analysis of AH level was found that AP from $160 / 100$ to $179 / 99 \mathrm{mmHg}$ statistically significant more frequent was found in group I - 71,2\% vs $47,1 \%(p=0,03)$, at the same time AP $180 / 110 \mathrm{mmHg}$ and higher was found more frequent in group II - 52,9\% vs $28,8 \%$ $(\mathrm{p}=0,02)$. Physical exertion tolerance, smoking did not differ $(\mathrm{p}>0,05)$ (Table 2).

In group II values of $\mathrm{sAP}(\mathrm{p}=0,001), \mathrm{pAP}(\mathrm{p}=0,001)$ и HR $(\mathrm{p}=0,001)$ were statistically significant higher than 
Table V. Lipid metabolism characteristics in patients with IHD and DM type II (Me [Q1; Q3])

\begin{tabular}{cccc}
\hline Indicator, unit & Група I, (n=66) & Група II, $(\mathbf{n = 3 4 )}$ & $\mathbf{P}$ \\
\hline $\mathrm{TC},(\mathrm{mg} / \mathrm{dl})$ & $233,5[224,5 ; 245,3]$ & $261,0[249,8 ; 277,0]$ & 0,001 \\
\hline $\mathrm{TG},(\mathrm{mmol} / \mathrm{l})$ & $167,5[156,0 ; 183,3]$ & $169,0[148,0 ; 184,3]$ & $>0,05$ \\
\hline $\mathrm{HDL},(\mathrm{mmol} / \mathrm{l})$ & $42,0[41,0 ; 43,0]$ & $42,0[41,0 ; 43,0]$ & $>0,05$ \\
\hline $\mathrm{LDL},(\mathrm{mmol} / \mathrm{l})$ & $159,0[148,6 ; 171,5]$ & $184,2[172,8 ; 197,7]$ & 0,001 \\
\hline $\mathrm{Al}$ & $4,6[4,3 ; 4,8]$ & $5,1[4,9 ; 5,7]$ & 0,001 \\
\hline
\end{tabular}

Table VI. Cardio-vascular ultrasound measurement in patients with IHD and DM type II (Me [Q1; Q3]).

\begin{tabular}{cccc}
\hline Indicator & Group I, $(\mathbf{n}=\mathbf{6 6})$ & Group II, $(\mathbf{n}=\mathbf{3 4})$ & $\mathbf{P}$ \\
\hline LALD, $\mathbf{m m}$ & $35,5[34,8 ; 36,6]$ & $37,2[36,0 ; 38,2]$ & 0,001 \\
\hline EdV, $\mathrm{ml}$ & $113,9[106,4 ; 123,8]$ & $115,5[107,3 ; 118,9]$ & $>0,05$ \\
\hline EsV, ml & $39,6[35,0 ; 44,1]$ & $41,9[37,9 ; 45,0]$ & $>0,05$ \\
\hline LV EF, \% & $66,3[64,4 ; 67,6]$ & $62,8[60,8 ; 66,4]$ & 0,001 \\
\hline Dt, sec & $0,24[0,22 ; 0,25]$ & $0,25[0,24 ; 0,26]$ & 0,001 \\
\hline IVRT, sec & $0,13[0,12 ; 0,14]$ & $0,14[0,13 ; 0,14]$ & $>0,05$ \\
\hline E/A ratio & $0,76[0,72 ; 0,78]$ & $0,69[0,64 ; 0,74]$ & 0,001 \\
\hline E/e', ratio. & $7,29[6,95 ; 7,67]$ & $7,38[6,61 ; 7,90]$ & $>0,05$ \\
\hline PA MP, mmHg. & $16,1[14,4 ; 17,7]$ & $17,0[16,0 ; 18,3]$ & 0,003 \\
\hline Brachial arteries EDD, \% & $9,00[8,50 ; 9,60]$ & $6,85[5,48 ; 9,25]$ & 0,001 \\
\hline
\end{tabular}

in group I (Table3). 6 min walk test had similar results in both groups $(p>0,05)$ (Table 3$)$.

Main factor, responsible for atherosclerosis in patient with DM type II is hyperglycemia. Comparing data in both groups, was found statistically significant higher $\mathrm{HbAlc}(\mathrm{p}=0,001)$, almost twice higher HOMA-ir $(\mathrm{p}=0,001)$, fasting glucose $(\mathrm{p}=0,004)$, postprandial glucose $(\mathrm{p}=0,002)$, insulin level $(\mathrm{p}=0,001)$ in group II (Table 4$)$.

Comparing lipid metabolism values in both groups, statistically significant higher values of TC $(p=0,001)$, LDL $(p=0,001)$, aterogenity index $(p=0,001)$ was found in group II. No difference was found between TG and HDL $(\mathrm{p}>0,05)$ (Table 5).

In group II $(\mathrm{n}=34)$ compared to group I $(\mathrm{n}=66)$ was found significant larger LALD ( $p=0,001)$. LV EF was preserved in both groups, but it was statistically significant lower in group II $(\mathrm{p}=0,001)$ (Table 6).

No difference in EsV and EdV was found ( $p>0,05)$. Significantly higher was PA MP $(p=0,003)$ and Dt $(p=0,001)$ in group II. $\mathrm{E} / \mathrm{A}$ ratio was higher in group $\mathrm{I}(\mathrm{p}=0,001)$, IVRT and $E / e^{\prime}$ ratio doesn 't differ in two groups $(p>0,05)$.

Brachial arteries EDD was higher in group I $(p=0,001)$ (Table 6).

Unfavorable outcome of CHF in patients with IHD and DM type II was associated with higher incidence of IHD and DM duration, also there was tendency of higher age.

In group II rates of DM type II family history, AP level was significantly high, also there was a tendency to higher incidence of IHD family history and lower physical exertion tolerance.

Unfavorable outcome of CHF was associated with more severe lipid and carbohydrate disturbances. Lipid metabolism disturbance leads to severe forms of DM type II.
Even if patients with CHD and DM type II have LV EF preserved, in case of unfavorable outcome EF was significantly lower and was a strong predictor of one.

All patients had left ventricle diastolic dysfunction 1 degree, despite normal LALD, but median was higher in group II. DT was higher in group II, that shows more severe diastolic dysfunction degree.

Group II is characterized by higher rate of endothelial dysfunction, that shows severe remodeling processes in vessels.

Studies on predicting the course and complications of various diseases in children and adults, surgical interventions, research of biological objects are very active [17 - 20] and on this basis, it is relevant to conduct such studies and to predict the course of $\mathrm{CHF}$ in patients with $\mathrm{CHD}$ and DM type II.

\section{CONCLUSIONS}

Severity of CHF with preserved LV EF in patients with IHD and DM type II is associated with disease duration, AH level and severity of lipid and carbohydrate metabolism disturbances.

Early markers of unfavorable outcome are: increase of DT and increases of PA MP even in range not higher than $20 \mathrm{mmHg}$.

\section{REFERENCES}

1. Severino P., D'Amato A., Netti L. et al. Diabetes Mellitus and Ischemic Heart Disease: The Role of lon Channels. Int J Mol Sci. 2018;19(3):802.

2. IDF Diabetes Atlas, 7th ed. 2015. http://www.diabetesatlas.org/ resources/2015-atlas. html. 
3. Kumar R., Kerins D.M., Walther T. Cardiovascular safety of anti-diabetic drugs. European Heart Journal. Cardiovascular Pharmacotherapy. 2015:202-208.

4. Stratton I.M., Adler A.I., Neil H.A. et al. Association of glycaemia with macrovascular and microvascular complications of type 2 diabetes (UKPDS 35): prospective, observational study. BMJ. 2000;321:405-412.

5. Chatterjee S., Khunti K., Davies M.J. Type 2 Diabetes and Cardiovascular Factors Contrasted with Fibrinolysis Disorders in the Blood of Patients with Peripheral Arterial Disease. Type 2 diabetes. Lancet. 2017;389(10085):2239-2251.

6. Bowes C.D., Lien L.F., Butler J. Clinical aspects of heart failure in individuals with diabetes. Diabetologia. 2019;62(9):1529-1538.

7. Jia G., Whaley-Connell A., Sowers J.R. Diabetic cardiomyopathy: a hyperglycaemia - and insulin-resistance-induced heart disease. Diabetologia. 2018;61(1):21-28.

8. Yahagi K., Kolodgie F.D., Lutter C. et al. Pathology of Human Coronary and Carotid Artery Atherosclerosis and Vascular Calcification in Diabetes Mellitus. Arterioscler Thromb Vasc Biol. 2017;37(2):191-204.

9. Saotome M., Ikoma T., Hasan P., Maekawa Y. Cardiac Insulin Resistance in Heart Failure: The Role of Mitochondrial Dynamics. Int J Mol Sci. 2019;20(14):3552.

10. 2016 ESC Guidelines for the diagnosis and treatment of acute and chronic heart failure: The Task Force for the Diagnosis and Treatment of Acute and Chronic Heart Failure of the European Society of Cardiology (ESC). Journal of Heart Failure. 2016;37: 2129-2200.

11. American diabetes association. Standards of Medical Care in Diabetes - 2017. Diabetes Care. 2017;40(1):135S.

12. Klimov A.N. Prichiny i usloviya razvitiya ateroskleroza. Preventivnaya kardiologiya 1977:260-321.

13. Sofa D.A., Hadyana S., Keri L., Rizky A. Medication Adherence Contributes to an Improved Quality of Life in Type 2 Diabetes Mellitus Patients: A Cross-Sectional Study. Diabetes Therapy. 2016;7:1-10.

14. Savarese G., Lund L.H. Global Public Health Burden of Heart Failure. Card. Fail. Rev. 2017;3:7-11.

15. Udell J.A., Cavender M.A., Bhatt D.L. et al. Glucose-lowering drugs or strategies and cardiovascular outcomes in patients with or at risk for type 2 diabetes: A meta-analysis of randomised controlled trials. Lancet Diabetes Endocrinol. 2015;3:356-366.

16. 2019 ESC Guidelines on diabetes, pre-diabetes, and cardiovascular diseases developed in collaboration with the EASD : The Task Force on diabetes, pre-diabetes, and cardiovascular diseases of the European Society of Cardiology (ESC) and developed in collaboration with the European Association for the Study of Diabetes (EASD). European Heart Journal. 2019: 1-69.
17. Vysotska 0., Dobrorodnia G., Gordiyenko N. et al. Studying the mechanisms of formation and development of overweight and obesity for diagnostic information system of obesity. Eastern-European Journal of Enterprise Technologies. 2016;6;2(84):15-23.

18. Lyzohub M., Georgiyants M., Vysotska 0. et al. Cardiovascular changes in humanbody after changing position supine to prone. Georgian Med News. 2019;(289):91-94.

19. Georgiyants, M., Khvysyuk 0., Boguslavska N. et al. Development of mathemapical model for the prediction of postoperative pain development among patients with limb injuries. Eastern-European Journal of Enterprise Technologies. 2017;2(4-86):4-9.

20. Vysotska 0., Nosov K., Georgiyants M. et al. An approach to determination of the criteria of harmony of biological objects. Proceedings of SPIE - The International Society for Optical Engineering. 2018.

\section{ORCID and contributionship:}

Ekaterina Yu. Lipakova: 0000-0002-4515-4260 A, B, D, E, F Oleksandr V. Bilchenko: 0000-0003-3313-2547 A, F

Tetiana A. Rudenko: 0000-0002-0193-250X C,F

Maksym O. Holianishchev: 0000-0002-5862-7418 ${ }^{B, E}$

Olena V. Vysotska: 0000-0003-3723-9771 B, C

Liubov M. Rysovana: 0000-0001-7937-4176 ${ }^{\text {B, C }}$

\section{Conflict of interest:}

The Authors declare no conflict of interest

\section{CORRESPONDING AUTHOR Ekaterina Yu. Lipakova \\ Kharkiv Medical Academy of Postgraduate Education \\ 58 Amosov St, 61176 Kharkiv, Ukraine \\ tel: +3804444473 \\ e-mail: ekaterinalipakova@gmail.com}

Received: 24.10 .2019

Accepted: 26.08 .2020

A - Work concept and design, B - Data collection and analysis, C - Responsibility for statistical analysis, $\mathbf{D}$-Writing the article, $\mathbf{E}$-Critical review, $\mathbf{F}$ - Final approval of the article 